\title{
Endoscopic endonasal cerebrospinal fluid rhinorrhea repair: a cohort study in Iraq
}

\author{
Ammar Abdulkadhim Hasan*, Saad Farhan Al-Saedi, Mukhallad Mahdi Saleh and Hani Musa Al-Akbi
}

\begin{abstract}
Background: Cerebrospinal fluid (CSF) rhinorrhea is a condition where the protective fluid that surrounds the brain finds its way into the nose and sinuses, often appearing as a very watery runny nose. The main surgical approaches for the surgical repair of CSF leaks are intracranial and extracranial. Over the last decade, endoscopic surgery has established itself as the most widely used technique for the repair of CSF fistula. The current study aimed to describe the use of nasal endoscopic technique in the management of cerebrospinal fluid rhinorrhea repair.

Results: Results of our study showed that in addition to CSF leak, 40\% of the patients had headache and 17.5\% had repeated meningitis. Half of the etiologies for the CSF leak were spontaneous, 35\% were congenital, and 15\% were traumatic. The more frequent site of leak was left cribriform plate (37.5\%). In the majority of patients, 37/40 (92.5\%), the type of graft was tensor fascia lata and fat, while in the remaining 3 patients, type of graft was tensor fascia lata and bone, bone and fat, and tensor fascia lata. The repair succeeded in 35 patients giving a success rate of $87.5 \%$.
\end{abstract}

Conclusion: It can be concluded that wide range of age groups from 2-62 years presented as CSF rhinorrhea with female predominance, and there was high success rate of endoscopic CSF rhinorrhea repair with low morbidity.

Keywords: Cohort study, Endoscopic-endonasal cerebrospinal fluid, Rhinorrhea repair

\section{Background}

Cerebrospinal fluid (CSF) rhinorrhea is a condition where the protective fluid that surrounds the brain finds its way into the nose and sinuses, often appearing as a very watery runny nose. Most cases of CSF rhinorrhea occur after major accidents where the bones of the face and skull experience significant trauma [1]. The main surgical approaches for the surgical repair of CSF leaks are intracranial and extracranial [2].

There has been a shift over the last 30 years while choosing the best approach given the advancements made in endoscopic techniques. The endoscopic-guided approach for repair of CSF rhinorrhea offers the benefit of both panoramic and detailed image of the site of surgery, in fact owing to the specific direction of view of endoscopic lens system. It is possible to inspect the circumference of the operating field at $360^{\circ}$ by rotating the

* Correspondence: dramarentsrg@gmail.com

Baghdad Medical City, Gazi Al-Harriri Hospital, Baghdad, Iraq telescope around its longitudinal axis which enable direct endonasal access to the anatomical structures at rhinobase without the need for cutaneous incision or cutting through bony segments and without dislodgement of bone structure [2].

Outcomes with endoscopic repair of CSF leaks are generally over $90 \%$ according to multiple studies [3-5]. The highest failure rates occur in individuals with spontaneous leaks and intracranial hypertension. However, management of this subset of patients is successful in over $(90 \%)$ at 3 years when intracranial hypertension is appropriately managed [6]. Unfortunately, CSF pressure cannot be checked periodically due to the invasive nature of lumbar punctures. Medical treatment with acetazolamide or frequent monitoring by neurosurgeons of implanted VP shunts is the best option at this time. Decreasing the underlying intracranial hypertension is essential for increasing success rates in patients with spontaneous CSF leaks [7]. 
Since Dandy [8] described the first case of intracranial repair of CSF rhinorrhea by way of a bi-frontal craniotomy, this approach remained the mainstream of surgical treatment until Dohlman [9] reported the first case treated with an extracranial non endoscopic approach by way of a naso-frontal incision. Since then, a variety of endonasal approaches has evolved. In 1952, Hirsch [10] performed the first transnasal approach to close a sphenoid sinus leak. Vrabec and Hallberg [11] undertook an intranasal approach to manage cribriform plate leaks in 1964. Wigand [12], in 1981, was the first to describe the use of an endoscope in the treatment of CSF rhinorrhea incurred during FESS. Mattox and Kennedy [13] reported their seven successful repairs with free grafts and defined the indication of endoscopic technique for CSF repair. With the rapid development of endoscopic instrumentation, which has markedly improved the visualization of the entire roof of the sinonasal region and contributed to the surgical technique. An increasing number of surgeons have begun using the endoscope to repair CSF leaks and skull defects [14].

The objective of this study was to describe the use of nasal endoscopic technique in the management of cerebrospinal fluid rhinorrhea repair.

\section{Methods}

\section{Study design and participants}

This cohort study was conducted during the period from March 2014 to November 2018 on 40 patients (11 males and 29 females) who were referred to the otolaryngology department at (Ghazi AL- Hariri hospital for surgical specialties - Baghdad / Medical city), with a possible clinical diagnosis of CSF rhinorrhea. Twenty patients had spontaneous rhinorrhea, 14 patients had congenital meningiocele, and 6 patients had post-traumatic rhinorrhea. The duration of symptoms ranged from 2 to 22 months. All patients had failed to respond to conservative treatment in form of acetazolamide to decrease intracranial pressure.

Patients underwent a thorough past medical history including history of meningitis and surgical history like previous sinus surgeries, trauma, drug and social history, history of unilateral watery nasal discharge, history of headache, postnasal salty dripping, repeated dry coughing, clinical history, in addition to examination and analysis of the glucose concentration of the nasal discharge. Moreover, all the patients underwent computed tomography $(\mathrm{CT})$ and magnetic resonance imaging (MRI).

Full otorhinolaryngological examination was done. Endoscopic examination was done using local decongestant in the form of xylometazoline nasal drops $0.1 \%$ and topical anesthesia in the form of lidocaine spray, with the aid of $0,30,70^{\circ}$ rigid scope.
All patients were sent for neurological assessments and optic disc examination for papilledema in cases of spontaneous CSF leak. Acetazolamide was taken in most of our patients especially those with traumatic CSF leak.

All surgeries were done under general (combined gas and intravenous drugs) anesthesia with oral endotracheal intubation.

When the patient recovered from the anesthesia, he/ she was transferred to the ward and kept under the following: hourly chart for monitoring the vital signs, head elevation $15^{\circ}$, broad spectrum antibiotics (injectable ceftraixone in a dose of $50-100 \mathrm{mg}$ per $\mathrm{kg}$ for 5 days), diuretics; at first day (injectable furosemide in a dose of 1$2 \mathrm{mg} / \mathrm{kg} /$ in three doses), then changed to oral acetazolamide in the second day. Moreover, a stool softener was given to decrease any possibility of increase intraabdominal pressure which may affect the procedure outcome. An oral antihistamine was given to suppress any sneezing that might increase intracranial pressure. Analgesic was given in the form of acetaminophen or tramadol (oral and injectable). Antiemetic and cough suppressant was given on need.

Patients stayed in the hospital until the nasal pack was removed. Kennedy Sinuspack which is used to prevent adhesion formation and post-operatory restenosis was usually removed at fifth to seventh day; once the packs were removed; medications were prescribed. Oral antibiotics were given for the next 10 days and oral acetazolamide was given for 1 month. Oral potassium supplement was given for 1 month (in conjunction with acetazolamide).

Patients were advised for a weekly visit in the first month and a monthly visit afterwards for endoscopic examination and assessment for at least 3 months.

\section{Inclusion/exclusion criteria}

Inclusion criteria to the study were traumatic CSF leak and non-traumatic CSF leak, while exclusion criteria were post-operative skull base tumor complicated by CSF rhinorrhea.

\section{Ethical considerations}

The study was approved by the (blinded for review). Moreover, confidentiality of all information collected in this study was guaranteed, as well as all data were protected through appropriate measures. Written informed consent was obtained from all participants.

\section{Statistical analysis}

Data of all patients were entered and managed using the statistical package for social sciences (SPSS) software (version 25). Descriptive statistics of the variables were expressed as mean, standard deviation, median, range, frequencies, and percentages. 


\section{Results}

Age and gender distribution of the studied groups is presented in Table 1. Females represented $(72.5 \%)$ of the studied group with a female to male ratio of almost (2.63:1). Additionally, 10 patients had their CSF leak since birth while the duration of CSF leak in the remaining 30 patients ranged between 2 and 22 months.

Table 2 summarizes the distribution of symptoms associated with CSF leak. Regarding the symptoms, in addition to CSF leak, 16(40\%) of the patients had headache, $7(17.5 \%)$ had repeated meningitis, 4 (10\%) had nasal obstruction, 2(5\%) had repeated cough, and 3 (7.5\%) patients had other symptoms including intraoperative leak, 3rd cranial nerve palsy, post-surgery leak; however, 8 (20\%) patients had CSF leak only with no other associated symptoms.

Table 3 summarizes the etiologies of CSF leak. Half of the patients had spontaneous CSF leak, 14(35\%) patients had congenital, and 6 (15\%) patients were traumatic; (5) of them surgical and the remaining 1 with head trauma.

As for the site of CSF leak, it is presented in Table 4. The more frequent site of leak was left cribriform plate which accounted for $37.5 \%$, followed by right cribriform plate (27.5\%). Left ethmoid sinus roof was the site of leak in $10 \%$, while each of right ethmoid sinus roof and sphenoid sinus accounted for $12.55 \%$.

Table 5 summarizes the Distribution of the studied group according to the size of defect. Meningocele was reported in $18(45 \%)$, recurrence in $5(12.5 \%)$ of cases, while skull base defect on CT was seen in $31(77.5 \%)$ of patients.

The distribution of the studied group according to the size of defect revealed that $3(8 \%)$ patients had a defect of more than $1 \mathrm{~cm}$ and the remaining 37 (92.5\%) patients were with a defect less than $1 \mathrm{~cm}$ as shown in Fig. 1.

In majority of patients, 37/40 (92.5\%), the type of graft was Tensor Fascia Lata (TFL) and fat while in the remaining $3(7.5 \%)$ patients, the type of graft was TFL and bone, bone and fat, and tensor fascia lata as shown in Fig. 2.

Table 1 Age and gender distribution of the studied groups

\begin{tabular}{lll}
\hline Variable & & \\
\hline Age & Mean \pm SD & $30.7 \pm 16.8$ \\
& Median & 31.5 \\
& Range & $2-62$ \\
Gender & Female, $n(\%)$ & $29(72.5)$ \\
& Male, $n(\%)$ & $11(27.5)$ \\
& Female to male ratio & $2.63: 1$ \\
Duration of CSF leak & Since birth, $n(\%)$ & $10(25)$ \\
& 2-22 months & $30(75 \%)$ \\
\hline
\end{tabular}

$S D$ standard deviation
Table 2 Distribution of symptoms associated with CSF leak

\begin{tabular}{lll}
\hline Symptom & No. & (\%) \\
\hline Headache & 16 & 40 \\
CSF leak only & 8 & 20 \\
Repeated meningitis & 7 & 17.5 \\
Nasal obstruction & 4 & 10 \\
Repeated cough & 2 & 5 \\
Other symptoms & 3 & 7.5 \\
Total & 40 & 100 \\
\hline
\end{tabular}

Distribution of the studied group according to the outcome of endoscopic endonasal repair is shown in Fig. 3, where the repair succeeded in 35 patients giving a success rate of $87.5 \%$. Four of the remaining 5 patients needed reoperation, 3 of them by endoscopic approach and 1 by craniotomy with complete cure of the 4 patients, while 1 patient was non-operated lost from follow-up.

\section{Discussion}

In our country, CSF rhinorrhea had been treated surgically by neurosurgeons using open approach (craniotomy) for many years with its high morbidities and mortalities.

In the last few years, a great move was done in our otolaryngology department at (blinded for review) for surgical specialties to treat such cases with CSF rhinorrhea by endonasal endoscopic approach. The present study tried to assess the use of nasal endoscopic technique in the management of cerebrospinal fluid rhinorrhea repair.

The mean age among the studied group was 30.7 years and this finding was close to that reported by Ta-Jen Lee et al. who found that the mean age was 36.8 years [15]. Arun Alexander et al. [16] reported that the age of the patients ranged from 6 to 61 years with a mean of 38.9 $( \pm 11.57)$ years.

In the present study, females represented 29 (72.5\%) of the studied group with a 2.63:1 female to male ratio. Yong-Gang Kong et al. [17] reported 17 males and 5 females among 22 cases. Muhammad Umar Farooq (2011) reported 13 males and 10 females among his 23 cases [18].

Table 3 Etiologies of CSF leak

\begin{tabular}{lll}
\hline Etiology & No. & (\%) \\
\hline Spontaneous & 20 & 50 \\
Congenital & 14 & 35 \\
Traumatic & 6 & 15 \\
Total & 40 & 100 \\
\hline
\end{tabular}

Traumatic: (5) surgical and (1) trauma 
Table 4 Site of CSF leak

\begin{tabular}{lll}
\hline Site of leak & No. & (\%) \\
\hline Left cribriform plate & 15 & 37.5 \\
Right cribriform plate & 11 & 27.5 \\
Left ethmoid sinus roof & 4 & 10 \\
Right ethmoid sinus roof & 5 & 12.5 \\
Sphenoid sinus & 5 & 12.5 \\
Total & 40 & 100 \\
\hline
\end{tabular}

In our study, 10 patients had their CSF leak since birth, while the duration of CSF leak in the remaining 30 patients ranged between 2 and 22 months. Mohamad R. Chaaban et al. [19] reported that the estimated duration of symptoms at presentation averaged 14.3 months (range 1-120 months).

Symptomatic evaluation of patients in the present study, in addition to CSF leak, revealed that $40 \%$ of the patients had headache, $17.5 \%$ had repeated meningitis, $10 \%$ had nasal obstruction, when compared with the study done by Araujo Filho et al., who found that the major symptoms encountered by patients were clear rhinorrhea (98\%), meningitis (9\%), and seizures (7\%) [20].

Regarding associated meningitis, it was found by Alexander, A. et al. that of the 34 patients with CSF rhinorrhea, 3 patients had a history of meningitis before surgery and was probably the reason for the diagnosis [16].

Our study reported that $50 \%$ of the patients had spontaneous CSF leak, 35\% congenital, 15\% traumatic, 5 of them surgical, and the remaining 1 patient with head trauma, which differs from the study conducted by TaJen Lee et al. [15] who reported that 51\% were traumatic, $15 \%$ spontaneous, and 33\% iatrogenic. Araujo Filho et al. [20] reported that (32\%) of the patients were traumatic and (39\%) were spontaneous.

Our study reported that left cribriform plate was the most common site $(37.5 \%)$, followed by right cribriform plate $(27.5 \%)$. Left ethmoid sinus roof was the site of leak in $10 \%$, while each of right ethmoid sinus roof and sphenoid sinus accounted for $12.55 \%$. In the study of Ta-Jen Lee et al. [15], it was shown that $33.3 \%$ were cribriform plate, $40 \%$ from the ethmoids roof, $18 \%$ from the

Table 5 Distribution of the studied group according to the size of defect

\begin{tabular}{llll}
\hline Finding & & No. & (\%) \\
\hline Meningiocele & Yes & 18 & 45 \\
Recurrence & No & 22 & 55 \\
& Yes & 5 & 12.5 \\
Skull defect & No & 35 & 87.5 \\
& Yes & 31 & 77.5 \\
& No & 9 & 22.5 \\
\hline
\end{tabular}

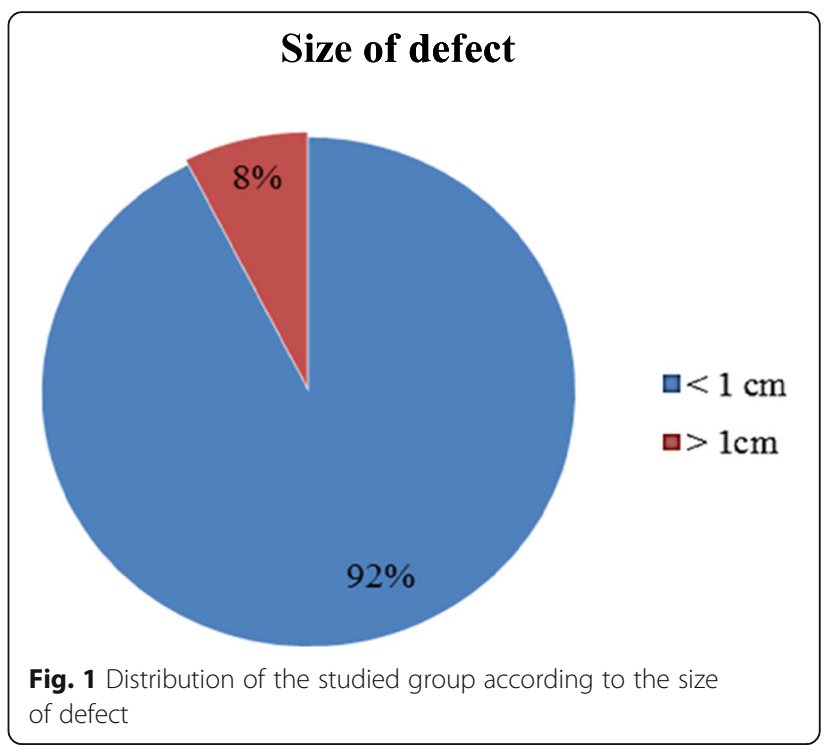

sphenoid, and $7.7 \%$ from the frontal sinus, while the study of Arun Alexander et al. [16] reported that fovea ethmoidalis was more common than cribriform plate with $55 \%$ and $29 \%$ respectively, while the frontal and sphenoid sinus was $5.9 \%$ for each.

Meningocele was present in $18(45 \%)$ of cases which agreed with Arun Alexander et al. who reported Meningoceles to be present in 14(41.1\%) of the patients [16]. Yong-Gang Kong et al. [17] found two cases among 22 patients.

Skull base defect on CT was seen in 31/40 patients, while the study of Mohamad R. Chaaban (2014) indicated that 21/45 subjects had radiographic evidence of skull base defect [19].

In the majority of the patients (92.5\%), the type of graft was TFL and fat while in the remaining 3 patients' type of graft was TFL and bone, bone and fat, and tensor fascia lata. The decision of type of graft depends on size of defect, if the size was less than $1 \mathrm{~cm}$ tensor fascia lata and fat was used. When the size of defect is more than 1

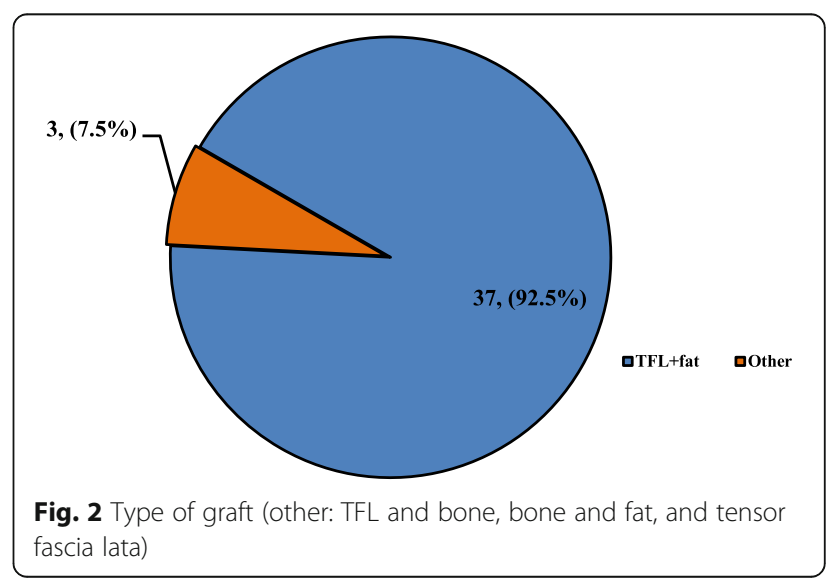




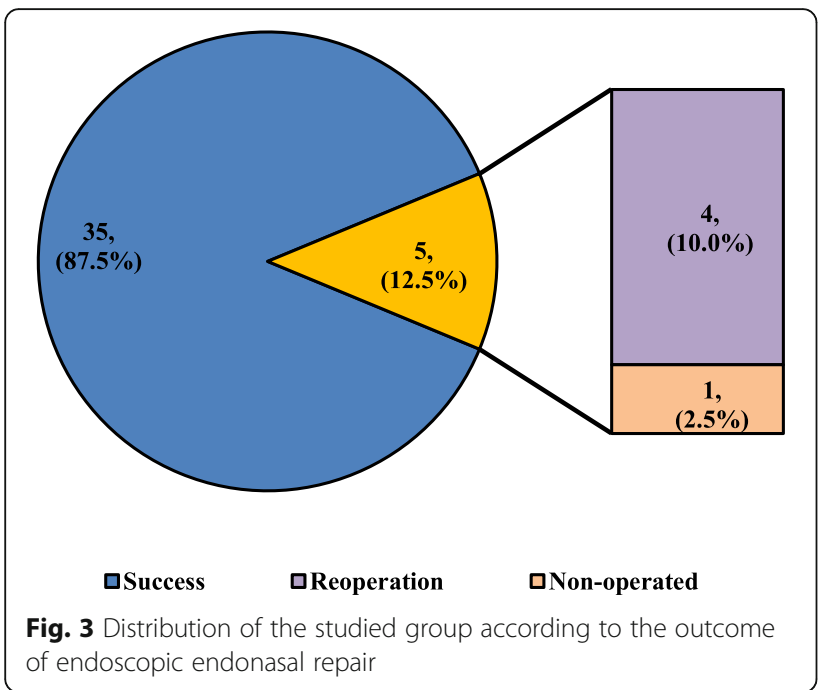

$\mathrm{cm}$, bone was added to the graft. We could not find other studies discussing the type of graft to compare their results with our results.

Success of surgery in the current study was indicated when the repair succeeded in 35 patients giving a success rate of $87.5 \%$. Four of the remaining 5 patients needed reoperation while 1 patient was non-operated, and 3 of them were reoperated by endoscopic approach and 1 by craniotomy which was closed by surgery, and 1 patient was lost from follow-up.

Successful endoscopic repairs were accomplished in $90 \%$ of patients during the first attempt as reported by Hegazy et al. [14]. Kirtane et al. [21] had success rate of 96.63\%. While many other studies reported more than $80 \%$ success rates $[20,22-25]$.

The results of this study should be evaluated in light of its strengths and limitations. Being among few hospitals which carry out this new surgical technique, describing this procedure is the main strength of our study. One of the limitations of the study was type of the research question which is descriptive in nature. This is due to the fact that this technique is still new and we do not have another group of patients to carry out a comparative study. Finally, the results of this paper might not be generalizable since the patients were selected from one hospital.

\section{Conclusion}

It can be concluded that wide range of age groups from 2 to 62 years presented as CSF rhinorrhea with female predominance, and there was high success rate of endoscopic CSF rhinorrhea repair with low morbidity.

\section{Abbreviations}

CSF: Cerebrospinal fluid; CT: Computed tomography; MRI: Magnetic resonance imaging; SPSS: Statistical Package for Social Sciences; TFL: Tensor fascia lata

\section{Acknowledgements}

Not applicable.

\section{Authors' contributions}

All authors contributed to the work. AH made substantial contributions to the conception and design of the work. SA carried out the statistical analysis. $\mathrm{AH}, \mathrm{MS}$, and $\mathrm{HA}$ have drafted and written the paper. All authors substantively revised it and approved the submitted version. All authors agreed to be personally accountable for each one's contributions. All authors ensure that questions related to the accuracy or integrity of any part of the work, even ones in which the author was not personally involved in, are appropriately investigated, resolved, and the resolution documented in the literature. All authors have read and approved the manuscript.

\section{Funding}

None.

\section{Availability of data and materials}

Not applicable.

\section{Declarations}

Ethics approval and consent to participate

The study was approved by the Arab Board Fellowship Skull Base Surgery. Moreover, confidentiality of all information collected in this study was guaranteed, as well as all data were protected through appropriate measures. Written informed consent was obtained from all participants. The Ethics Committee reference number is not applicable.

\section{Consent for publication}

Not applicable.

\section{Competing interests}

The authors declare that they have no competing interests.

Received: 24 April 2021 Accepted: 29 June 2021

Published online: 27 July 2021

\section{References}

1. Clinic C (2019) Cerebrospinal Fluid (CSF) Leak. Cleveland Clinic medical professional, Cleveland Clinic https://my.clevelandclinic.org/health/disea ses/16854-cerebrospinal-fluid-csf-leak

2. Paolo Castelnuovo DL (2005) Endosopic surgical management of cerebrospinal fluid Rhinorrhea. Endopress Publisher, Germany

3. Schlosser RJ, Bolger WE (2004) Nasal cerebrospinal fluid leaks: critical review and surgical considerations. Laryngoscope 114(2):255-265. https://doi.org/1 0.1097/00005537-200402000-00015

4. Mishra SK, Mathew GA, Paul RR, Asif SK, John M, Varghese AM, Kurien M (2016) Endoscopic repair of CSF rhinorrhea: an institutional experience. Iran J Otorhinolaryngol 28(84):39-43

5. Tosun F, Carrau RL, Snyderman CH, Kassam A, Celin S, Schaitkin B (2003) Endonasal endoscopic repair of cerebrospinal fluid leaks of the sphenoid sinus. Arch Otolaryngol Head Neck Surg 129(5):576-580. https://doi.org/10.1 001/archotol.129.5.576

6. Komisar A, Weitz S, Ruben RJ (1983) Cerebrospinal fluid dynamics and rhinorrhea: the role of shunting in repair. Otolaryngol Head Neck Surg 91(4): 399-403. https://doi.org/10.1177/019459988309100410

7. Huff T, Tadi P, Varacallo M (2020) Neuroanatomy, cerebrospinal fluid. In: StatPearls, Treasure Island. Endopress Publisher, Germany

8. Dandy WE (1926) Pneumocephalus (intracranial pneumocele or aerocele). Arch Surg 12(5):949-982. https://doi.org/10.1001/archsurg.1926.01130050003 001

9. Dohlman G (1948) Spontaneous cerebrospinal rhinorrhoea; case operated by rhinologic methods. Acta Otolaryngol Suppl 67(sup67):20-23. https://doi. org/10.3109/00016484809129635

10. Hirsch O (1952) Successful closure of cerebrospinal fluid rhinorrhea by endonasal surgery. AMA Arch Otolaryngol 56(1):1-12. https://doi.org/10.1 001/archotol.1952.00710020018001

11. Vrabec DP, Hallberg OE (1964) Cerebrospinal fluid rhinorrhea. intranasal approach, review of the literature, and report of a case. Arch Otolaryngol 80(2):218-229. https://doi.org/10.1001/archotol.1964.00750040224022 
12. Wigand ME (1981) Transnasal ethmoidectomy under endoscopical control. Rhinology 19(1):7-15

13. Mattox DE, Kennedy DW (1990) Endoscopic management of cerebrospinal fluid leaks and cephaloceles. Laryngoscope 100(8):857-862. https://doi.org/1 0.1288/00005537-199008000-00012

14. Hegazy HM, Carrau RL, Snyderman CH, Kassam A, Zweig J (2000) Transnasal endoscopic repair of cerebrospinal fluid rhinorrhea: a meta-analysis. Laryngoscope 110(7):1166-1172. https://doi.org/10.1097/00005537-2 00007000-00019

15. Lee TJ, Huang CC, Chuang CC, Huang SF (2004) Transnasal endoscopic repair of cerebrospinal fluid rhinorrhea and skull base defect: ten-year experience. Laryngoscope 114(8):1475-1481. https://doi.org/10.1097/ 00005537-200408000-00029

16. Alexander A, Mathew J, Varghese AM, Ganesan S (2016) Endoscopic repair of CSF Fistulae: A Ten Year Experience. J Clin Diagn Res 10(8):MC01-MC04. https://doi.org/10.7860/JCDR/2016/18903.8390

17. Kong YG, Deng YQ, Wang Y (2013) Transnasal endoscopic repair of cerebrospinal fluid rhinorrhea: an analysis of 22 cases. Indian J Otolaryngol Head Neck Surg 65(Suppl 2):409-414. https://doi.org/10.1007/s12070-0130628-8

18. Farooq MU, Ansari MA (2011) Cerebrospinal fluid rhinorrhea: etiology, site of leakage and endoscopic management. J Coll Physicians Surg Pak 21(8):460463. https://doi.org/10.1097/00005537-200402000-00015

19. Chaaban MR, Illing E, Riley KO, Woodworth BA (2014) Spontaneous cerebrospinal fluid leak repair: a five-year prospective evaluation. Laryngoscope 124(1):70-75. https://doi.org/10.1002/lary.24160

20. Araujo Filho BC, Butugan O, Padua FG, Voegels RL (2005) Endoscopic repair of CSF rhinorrhea: experience of 44 cases. Braz J Otorhinolaryngol 71(4): 472-476. https://doi.org/10.1016/s1808-8694(15)31202-7

21. Kirtane MV, Gautham K, Upadhyaya SR (2005) Endoscopic CSF rhinorrhea closure: our experience in 267 cases. Otolaryngol Head Neck Surg 132(2): 208-212. https://doi.org/10.1016/j.otohns.2004.09.004

22. Schick B, Ibing R, Brors D, Draf W (2001) Long-term study of endonasal duraplasty and review of the literature. Ann Otol Rhinol Laryngol 110(2): 142-147. https://doi.org/10.1177/000348940111000209

23. Burns JA, Dodson EE, Gross CW (1996) Transnasal endoscopic repair of cranionasal fistulae: a refined technique with long-term follow-up. Laryngoscope 106(9 Pt 1):1080-1083. https://doi.org/10.1097/00005537-1 99609000-00007

24. Reyt ERC, Colombani JM, Favre JJ (1997) Transnasal endoscopic identification and repair of cerebrospinal rhinorrhoea. Skull Base Surgery 7(Suppl 2):52

25. Hao SP (1996) Transnasal endoscopic repair of cerebrospinal fluid rhinorrhea: an interposition technique. Laryngoscope 106(4):501-503. https://doi.org/10.1097/00005537-199604000-00021

\section{Publisher's Note}

Springer Nature remains neutral with regard to jurisdictional claims in published maps and institutional affiliations.

\section{Submit your manuscript to a SpringerOpen ${ }^{\circ}$ journal and benefit from:}

- Convenient online submission

- Rigorous peer review

- Open access: articles freely available online

- High visibility within the field

- Retaining the copyright to your article

Submit your next manuscript at $\boldsymbol{\nabla}$ springeropen.com 